\title{
Okra in translation
}

\section{Asylum seekers, food, and integration}

\author{
Andrea Ciribuco \\ National University of Ireland Galway
}

This article explores the theme of food translation, based on research conducted in Italy in 2018 with a group of asylum seekers from different West African countries. It concentrates on a community gardening project revolving around the cultivation of okra: a vegetable that is a staple in many African cuisines, but not very popular in Italy, which provided the occasion for the participants to communicate their home foodways.

As something that is linked to the most basic human needs, and yet bears high cultural significance, food can be used as a lens to explore the shifting relationship between language and other embodied forms of meaning. Translating food means engaging with a complex interplay of language, sensory experiences, and socio-cultural norms. Drawing from recent semiotically-oriented developments in translation studies as well as applied linguistics, and the semiotics of food, I analyze key participants' involvement with the project.

Keywords: food, translation, refugee, asylum, intersemiotic translation, Italy

\section{Introduction}

Food is a crucial factor in human well-being, and an immediate signifier of cultural belonging in contexts of migration. As a tangible sign of difference, it plays a crucial part in the cohabitation of individuals from different backgrounds, where the presence of different foods side by side can generate ethnocentric diffidence or cosmopolitan curiosity. Food is shared, reinterpreted, misunderstood - and in so doing, translated. 'Translating food' means confronting a complex interplay of language(s), sensory experience, and socio-cultural norms, to be rendered in a different language or mode of communication. This includes the choice of how to translate food terms across different languages and registers; 
but also the translation of words into food (while following a recipe) or food's taste, smell etc. into words.

This article explores the role that food translation had for a group of asylum seekers who were involved in a community gardening project with the NonGovernmental Organisation Tamat in 2018 in Perugia (Italy). The article analyses interactions between asylum seekers and social workers in the field, as well as an interview with key participants. It looks at how participants developed strategies to translate food-related meaning from their background; and in so doing, evolve their relationship with social workers and other residents. The different strategies that emerged showed how the strategies for translating migrant food relate to different semiotic systems, but also to relations of power that exist between 'guests' and 'hosts' in a community.

\section{Translation and refugee integration}

There are different ways of looking at translation in contexts of migration and asylum. One presupposes translation as performed by a (semi)professional individual reformulating a specific oral/verbal text into another language - which is vital in many contexts of asylum, such as hospitals, reception centres, and asylum courts (Inghilleri, 2005; Jiménez-Ivars \& León-Pinilla, 2018). It is also possible to see translation as a ubiquitous activity in the everyday life of a migrant or refugee, a survival mechanism in diverse neighbourhoods (Flynn \& van Doorslaer, 2016). The latter view of translation does not deny the former; rather, it inscribes the work of (semi)professional translators within a wider framework, where translation has to do with the human capacity to transform meaning, and with the migrant's quest for mutual understanding. The political dimension of translation invests not only issues such as courtroom interpreting (crucial as they are for asylum seekers), but the possibility of being acknowledged as translating subjects, and not only as the 'living source texts' of translation.

Combining theoretical tools from translation studies and sociolinguistics is increasingly proving effective in developing a more complete look at multilingual interactions: that goes hand in hand with the acknowledgement that translation is not only the intellectual journey of a professional, but a force linked to everyday discursive and political inequalities in material contexts. In diverse urban spaces, translation often coexists with other forms of everyday language contact such as translanguaging (Creese, Blackledge, \& Hu, 2018). With its emphasis on the context of interaction, and on individuals' creative use of their communicative repertoires, the translanguaging model "can be a way of understanding the routine moment-to-moment flux and bricolage of translating as an activity, where trans- 
lators draw on their multilingual repertoire and artefacts in the environment" (Baynham \& Lee, 2019, p.53). As the interactions described in this article will underline, contact between refugees and the landscape involves similar continua of negotiations.

If we take a comprehensive look at the role of translation in the lives of refugees, it could be how they bring new meaning into the host landscape; or the way in which the host society integrates them, turning 'marked' meaning into 'unmarked' mainstream discourse, with the risk that "integration and translation (into the dominant host language and culture) become increasingly synonymous" (Cronin \& Simon, 2014: 131). Sociolinguistic research expresses compatible preoccupations with the notion of integration: integration, despite being promoted as an inclusive concept, is often associated with the creation of "subaltern 'others" within the monolingual state (Flubacher \& Yeung, 2016:606). From a linguistic point of view, the burden is on these "others" to learn the host language, or be "accused not only of laziness but of self-isolation, of a failure to embrace their new community, of duplicitous disloyalty" (Piller, 2016:50). In translation theory, Inghilleri (2017:31) proposes to counter such assimilationist views using the idea of translation as "linguistic hospitality": a concept proposed originally by Ricœur (2006) as the ethical and communicative work of willingly residing in someone else's language. The metaphor of hospitality, however, can also identify the double and ambiguous performance of welcoming someone, while framing the 'guest' as an 'Other' in linguistic and cultural terms - as Vigouroux (2019) notes, building on Derrida. In the socio-political reality of migration and asylum, it is very often this latter meaning of hospitality that is at play, rather than Ricœur's intellectual "happiness" of a translator who takes the irreducibility of languages as starting point to welcome "the foreign word [...] in one's own welcoming house" (2006: 10).

My view of translation here is also influenced by Marais' recent call for translation studies to expand its focus and concentrate on what is broadly "translational" in reality:

Can smell be translated into sound? How are biochemical signs translated into electro-magnetic signs? What kind of reality does translation studies construct if it never deals with the translation of touch, smell or taste? Current translation studies is not able to answer this kind of questions.

(Marais, 2019:55)

Marais bases this theoretical expansion of translation on Peirce's semiotics and his notion that the meaning of a sign is its translation into another sign: translation can be understood as a process through which meaning (not necessarily linguistic meaning) gets reformulated into other meaning. In this view, translation is not the rewording of an oral or written text, but a potentially endless chain of reformulations linking different types of signs, which makes it a fundamental component 
of communication. From a Peircean perspective, Gal argues, translation encompasses a variety of semiotic processes where something changes its meaning while retaining part of it: "interdiscursive practices that are generative, producing new objects, practices, person-types, and knowledge" (2015: 236). In an asylum seeker's daily quest to understand and be understood in the new landscape, the ability to reframe meaning across semiotic systems (gestures, written signs, oral/written speech in many languages...) influences countless micro-encounters which, in the long run, determine their ability to negotiate the terms of hospitality.

\section{Translating food}

Semiotics has reflected on the meaning of food for a long time. Barthes (1961:980) already stated the importance of looking at food as a system of signs. We all refer to a grammar of food that variably interacts with, is disseminated through, and influences language. From prayers before family meals to discourses of genuineness in advertising, food and language influence each other as "codependent systems of meaning and value production" (Karrebæk, Riley, \& Cavanaugh, 2018:26). Semiotically speaking, food and language contribute to "index social, cultural, and emotional meanings across the range of contexts in which they cooccur" while being caught in economic distinctions among different producers and consumers (Riley \& Cavanaugh, 2017). One famous example is Silverstein's observation of how specific registers of wine-talk could index-make communicatively relevant in the here and now - the social status of wine drinkers (2006, 2016). As people move around the globe, food also indexes origins as we "learn to attach those foods and speech patterns to those people, places, and times, constructing symbolic and eventually iconicized stereotypes of who people are" (Riley \& Cavanaugh, 2017:8).

The meaning of food is ramified, at once embodied in a person's sense of smell and taste, and discussed and performed with others in a shared environment. Ingredients, dishes, and practices carry meaning, and this meaning becomes particularly evident when confronting unfamiliar foodways (Parasecoli, 2011). Järlehed and Moriarty (2018) use the concept of the semiofoodscape to define the relationship between semiotic resources that links food and a landscape. That is particularly important in contexts of migration and asylum, where individuals bring with them complex discourses about the cooking and consumption of specific foods, while confronting semiofoodscapes where those foods may be absent or frowned upon. The meaning of food shifts when individuals confront unfamiliar foods in convivial settings (Karrebæk, 2017), often struggling between faithfulness to their own grammar of food and that of the host country (Greco, 2016). 
Because of the complex ramifications of food's meaning, the transmission and reframing of food discourses often represents a particular challenge from a translator's point of view. Food may apparently resist translation, because food-related words always point to meaning that is at one time embodied and linked to sociocultural norms, for which there may be no ready-made words in the target language (Garzone, 2017). That does not make food-related language untranslatable, but it requires the translating individual to engage deeply with the complexity of food's meaning. Challenges include rendering tastes that one has never tasted, as well as the indexical meanings that may be associated with them.

Spurred by a 2015 special issue of The Translator (Chiaro \& Rossato, 2015), translation studies grew an interest in the translation of food-related texts, such as guidebooks (De Marco, 2015) or menus (Desjardins, Cooke, \& Charron, 2015; Li, 2019). These studies underline how the textual must always consider its relationship with a complex array of experiences and food-related discourse that are not easily contained in a string of words. Food can be used as a lens to explore translation as dynamic relation between different types of meaning in place.

An expansion of translation studies in the semiotic sense must consider food as a key factor in the relation between human language and the surrounding environment. Looking at translation as a continuum of transformations enables us to look past seemingly untranslatable food-related words, to concentrate on the wider array of meaning that language attempts to translate. How does the meaning of food shift as it moves both from the embodied semiosis of smell and flavour into the linguistic realm, and then - only then - from language to language? As migrants and refugees move around, encountering new foodways and bringing their old foodways with them, looking at food in translation helps us understand the politics of hospitality.

\section{Context and methodology}

\subsection{The Italian refugee hospitality program}

Between 2014 and 2018, 648,117 individuals reached Italy after crossing the Mediterranean, applying for asylum. ${ }^{1}$ The main nationalities for the years 2014-2017 were Eritrea, Nigeria, Syria, Mali, Guinea, Côte d'Ivoire, Gambia, Somalia, Senegal, Sudan (IDOS, 2017:122). The presence of asylum seekers has generated a tense debate in the population, divided between a representation of

1. Elaborated from UNHCR data, available at https://data2.unhcr.org/en/situations /mediterranean/location/5205 (accessed May 29, 2020) 
the newcomers as threats to national security or as victims: a dichotomy that has catalyzed sentiments of diffidence or compassion, but leaves little space for the asylum seekers' self-expression (Musarò \& Parmiggiani, 2017). In the meantime, "therapeutic, bureaucratic, and religious apparatuses" turn asylum seekers "into political categories - the migrant, refugee, and victim - that the state can recognize and use to legitimize their difference" (Giordano, 2014:10). Institutional actors translate the asylum seekers' stories to fit legal frameworks to accept or reject their claims.

Refugee hospitality programs feed and shelter the asylum seekers while institutional processes take place. ${ }^{2}$ These programs include "integration" services, variably interpreted as Italian language classes, or as training in professions in high demand in the Italian job market - generally manual jobs. The role of NGOs, charitable institutions and associations that provide these services is quite delicate as their staff may be highly motivated by beliefs in refugee rights, but at the same time participate to various extents in the infrastructure that regulates difference in the state, and promotes a view of integration that maintains the social order (Del Percio, 2016). As a demonstration of "integration" having heavy political connotations, a new Italian government issued a decree in late 2018 that, among other things, restricted linguistic and vocational training to those who already had refugee status. This limited most programs to providing food and shelter to asylum seekers who were waiting for the outcome of their application (and therefore did not know if they would be able to take part in the job market that requires these skills). The present research took place when these changes were about to unfold but had no concrete effect yet.

\subsection{Context for this study}

This research is part of a project investigating language and translation in the lives of a group of African asylum seekers in Perugia (pop.165,583), in central Italy. The project explores how migrants and refugees adapt and translate themselves to communicate with the host society; and what elements from the home language and culture resist translation into Italian and continue playing a role in the

2. As of 2018, Italian asylum seeker hospitality included two separate strands: SPRAR - Sistema Protezione Richiedenti Asilo e Rifugiati ("Asylum Seekers and Refugees Protection Service"), and CAS-Centro Accoglienza Straordinaria ("Emergency Hospitality Centre"). SPRAR was officially the main strand of refugee hospitality services, with a focus on education and training; CAS was originally an 'emergency' service, but it gradually became the most common. In 2018 , SPRAR was renamed SIPROIMI - Sistema di protezione per titolari di protezione internazionale e per i minori stranieri non accompagnati ("Protection System for Beneficiaries of International Protection and Unaccompanied Foreign Minors"). 
migrant's expressive life. As part of the research project, I also assumed the role of Italian language teacher in training and integration projects aimed at refugees and asylum seekers (October 2017-October 2019).

I will concentrate here in particular on Tamat's Urbagri4Women project, financed by the EU's Asylum Migration and Integration Fund, which combined agricultural training with other activities such as language teaching and collaborations with local associations. Tamat is a development organisation that operates in Africa and South America as well as Italy, with agricultural expertise: therefore, their approach to the theme of refugee integration was declined mainly in this sense. Urbagri4Women was especially aimed at migrant and refugee women; in the training phase a small number of men, mostly friends and partners of women in the group, were admitted to classroom activities. After the training ended, Tamat sponsored the creation of an Urban Agricultural Lab (henceforth UAL) in Montemorcino, a plot of land owned by the Catholic church within the boundaries of the town, where the project beneficiaries could grow vegetables for the use of their own community (Figure 1). The main crop was okra, which is a staple of many West African cuisines and yet is sold in very few shops in Perugia. This created a more open environment with respect to the classroom activities: the beneficiaries (men and women) who decided to be involved took part actively in the decisional process, and tasks were divided between them and Tamat's staff. Out of 34 students from the training modules, 7 stayed and took part in the UAL activities (three women and four men, coming from Guinea, Sierra Leone, Mali, Nigeria, Venezuela, Gambia).

The UAL operated in a key sector: agriculture is one of the most common forms of informal employment for asylum seekers and other disadvantaged migrants in Italy, and one where several human rights violations occur (Ceccarelli \& Ciconte, 2018). Within the Italian context, Urbagri4Women represented a particular (while not by any means unique) case, as it was not directly connected to the state apparatus of refugee hospitality. The project's self-avowed goal, and the justification of its funding, were social inclusion activities, and Tamat were not involved in any form of hospitality (food, shelter etc.), control or legal assistance for the asylum seekers involved. Participants were not assigned to the project by the state (as it would happen in a SPRAR) and had to be recruited among the local refugee population, with limited involvement from refugee hospitality organisations. This allowed Tamat a degree of freedom in developing their own ideas of how to 'integrate' the beneficiaries; even though they were still bound to the productivity logic of external funding and the need to concretely demonstrate their performance through indicators, such as the number of individuals involved. 


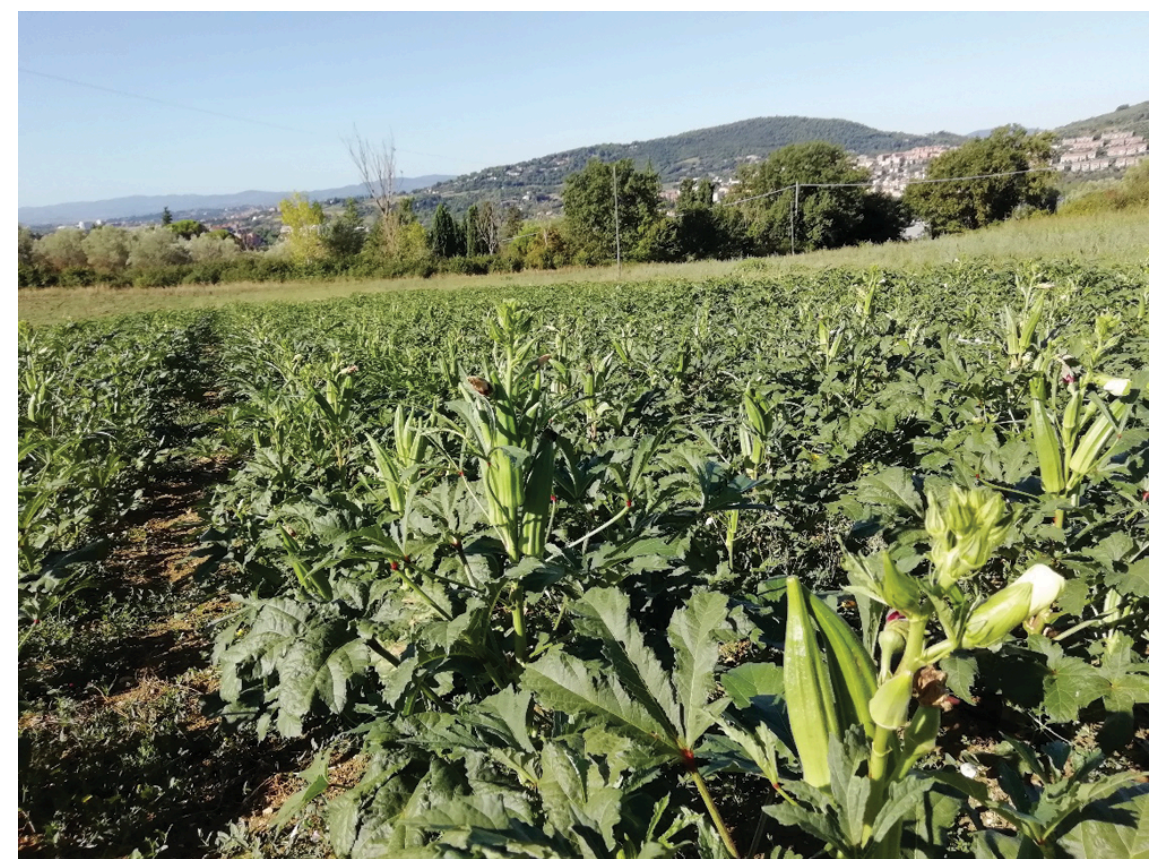

Figure 1. Picture taken by the author, 28 August 2018

\subsection{Research methodology and rationale}

The ethnographic method, employed in translation studies for the analysis of communities of practice (Flynn, 2010; Tesseur, 2017), enabled me to understand the practical relevance of translation in contexts of asylum, as well as refugees' attitudes towards translation and intercultural communication. Through my involvement as a teacher in Urbagri4Women, I researched the way in which the beneficiaries' rich and diverse multilingual repertoires interacted with the specialized language of Italian agriculture. The research was supervised in its ethical aspects by the Research Ethics Committee at NUI Galway, with agreements in place to protect the participants' privacy and well-being. During Urbagri4Women, the beneficiaries were informed about my double role as a teacher and university researcher, with the help of professional mediators and of Tamat's staff. I audio-recorded twelve classes between March and May 2018 and took research notes between November 2017 and September 2018 (about 47,000 words).

The preliminary results of the classroom study were presented in (Ciribuco, 2020), which mostly underlined the difficulties in translation occurring between the students and the social workers and educators in the context of the language 
classroom. This regarded especially concepts from the students' home countries, which they were often used to discussing only in one of several African languages in their repertoires, and had to be negotiated in Italian with the help of colonial languages (French, English). If my work had started as the analysis of the asylum seekers' journey through the Italian language, it quickly became apparent how the complexity of their linguistic repertoires represented value that needed to be acknowledged and brought in dialogue with their use of Italian. That is a crucial part of the participation of refugees in the language ecosystem of the host country, and it cannot happen without considering the challenge of translating across local languages and the refugees' repertoires. The preliminary results included a recommendation for language teachers to consider the use of "slow translation" (Cronin, 2017) to engage with the lived experience that created those complex linguistic repertoires.

As the activities of Urbagri4Women moved from the classroom to community gardening, I continued my research, maintaining my role as a language teacher in the community garden activities, where my role was gradually limited to mediating short interactions between the participants and the rest of the Italian staff (social workers, agronomists), while taking part in different agricultural activities. We engaged in a more complex translation ecosystem, where corporeality and embodied meaning became gradually more important than the languages at play. While an exclusive focus on interlingual translation (as in Ciribuco, 2020) can point to difficulties in translation that are rooted in environmental and cultural factors, in this article I turn to semiotics to understand the different types of meaning involved in the expression "translating food" and the relevance it may have in the relation between refugees and the landscape.

This article includes the impressions and points of view of two key participants, Giuli and Bouliwell. ${ }^{3}$ The two men had arrived in Italy (from Sierra Leone and Guinea respectively) through the Mediterranean route and became friends in Perugia. While coming from an Anglophone and a Francophone country respectively, they bonded over their common native language Pular, which is spoken by the Fula populations living across Guinea, Guinea-Bissau, Sierra Leone, and Mali. Giuli attended the Urbagri4Women training because he was invited by a woman with whom he was friends; Bouliwell joined the agricultural activities in the summer of 2018, having been invited in turn by Giuli. While most participants from the classroom stage of the project left, Giuli and Bouliwell quickly became key figures in the UAL, often discussing the cultivation strategies as well as the socioeconomic opportunities of community gardening with Tamat's staff.

3. All names in the article are pseudonyms. 
In August 2018, Giuli volunteered to take part in a local farmers' market, bringing some crates of okra to present the product to the public and raise funds for the project. In November 2018, I carried out a semi-structured interview in Italian ( 58 minutes) with the two key participants, which was audio-recorded and then transcribed, where we discussed their impression on Urbagri4Women and the strategies that they adopted to translate food.

\subsection{A note on okra in Italy}

Abelmoschus Esculentus is cultivated in warm areas of the world for its edible seed pods. These appear as green, elongated fruits with a pentagonal cross-section, containing white seeds and a viscous substance. Its English language name okra comes from West Africa (see Igbo okuiru.$_{.}^{4}$ Italian dictionaries recognize the plant as gombo, abelmosco or ocra, although there is some potential confusion in the fact that the Italian ocra most commonly refers to the pigment known in English as ochre. ${ }^{5}$ Terminological uncertainties depend on the fact that this global vegetable is virtually unknown by the Italian public. Although one may find some sparse okra cultivation in southern Italy, the fruits do not have a significant presence on Italian tables; it is virtually impossible to find it in the vegetable aisles of major Italian supermarket chains. Okra constitutes, however, one of the food staples of several immigrant communities in Italian cities and towns. As such, it does not carry the same meaning for most Italian residents of Perugia that it has for Nigerian or Bangladeshi residents of the town, who have it in their "grammar of food" (Greco, 2016).

Okra is one of the most characterizing merchandises on sale in grocery stores managed by African owners in the diverse neighbourhood of Fontivegge in Perugia. Ethnically characterized shops have a special function in the everyday lives of migrants as they enable connection to ethnic roots, tapping into both collective and individual memory (Sen, 2016:75). Many asylum seekers in Italy live in catered hospitality centres that generally serve Italian food, and only a small percentage live in self-catered accommodation where they can cook to their taste. During field work, I have often heard informants from self-catered centres talk about their visits to the African shop in Fontivegge, even if some lived as far as

4. “okra, n.." OED Online. March 2020. Oxford University Press. https://www.oed.com/view /Entry/130943?redirectedFrom=okra (accessed May 29, 2020).

5. The online Treccani dictionary, for example, has entries for gombo, bamia and abelmosco, although only the latter (http://www.treccani.it/vocabolario/abelmosco/ accessed May 15, 2020) indicates that the plant is edible; entries gombo and bamia only describe the plant as a source of textile fibres. 
45 minutes away by train. The effort to maintain familiar food codes and practices is common to most experiences of migration, as a way of affirming social networks and a sense of belonging, and countering potentially disruptive assimilation into the host country (Abbots, 2011). It is also important to remember that the arrival of a foreign food can always be perceived by locals, on the other hand, as an attack to local semiofoodscapes, as it is the case with kebab shops in Italy that can generate strong reactions, stirring anxieties about migration and globalization (Cavanaugh, 2013).

\section{In the field}

Urbagri4Women classroom training consisted in frontal lectures, with a rigid distinction between teachers and students: despite efforts to create an exchange, the focus was on Italian as a crucial communicative resource for the students' mobility (see Blommaert, 2010; De Costa, 2010), presenting specific vocabulary and registers that would ideally enable them to function in the Italian job market (Del Percio, 2018a, 2018b). The UAL, designed as an experimentation to determine whether okra would grow in Perugia, also introduced greater elements of collegiality and responsibility-sharing between the NGO workers and the asylum seekers. This did not eliminate the social and communicative distance; but the practical nature of the task, together with the asylum seekers' extensive knowledge of okra cultivation and use, created different forms of confrontation.

In ad-hoc meetings in June 2018, the participants were explained that in this new phase of the project they could contribute as much time as they wanted, and that decisions on the cultivation and subsequent use of okra would be taken collectively. Many who had attended the classroom training did not eventually take part in the UAL: reasons cited included other work or educational commitments, relocations, or loss of interest. For others who chose to take part, responsibilitysharing proved initially difficult. Some would continue to ask permission before taking any initiative (such as watering the plants), which would require the NGO workers to remind them that they were free to self-organise. It is important to note that, at the beginning, most initiatives still came from the NGO project manager, which may have reinforced the feeling that he was in charge; it was not until August 2018 at least, that it became common for participants to weigh in on the activities and provide alternative viewpoints.

Something that made evident the difficulties and contradictions in responsibility-sharing was the directionality of translation. NGO workers rarely describe themselves as translators, but are generally quite used to working with "messy, complex, informal and unplanned combination of languages, community 
practices, power relationships and motivations (both internal and external)" (Hamaidia, Methven, \& Woodin, 2018:120). Footitt and colleagues (2020) note how translation is not often explicitly a concern for international NGOs, who may or may not have multilingual and/or explicitly trained staff, with the risk that the beneficiaries' voices will be silenced, especially if expressed in minoritized languages. For organisations working with refugees in the host country, the issue is often how to build alternative strategies of inclusiveness and democratization that can cut across the inevitable power inequality between refugees and different types of 'helpers' (Carlsen, Doerr, \& Toubøl, 2020). In the Urbagri4Women garden, interlingual translation practices reveal how, notwithstanding the efforts of the NGO staff in this sense, there was still a communicative hierarchy in place. Tamat issued Italian communications with English translations in the participants' WhatsApp group; in the field, I would often be asked to translate verbally into English or French. To this extent, much of the interlingual translation still was controlled and initiated from the Italian side, with the goal of making other participants familiar with the 'appropriate' Italian terms by relying on a lingua franca. However, at the ground level of the UAL, the 'messy' nature of communications brought to life different layers and forms of translation, where the participants' skills and knowledge played an important role.

Early in the realization of the UAL, I was with Ousmane, a man from Gambia, and after a quick inspection we decided that we needed to take out weeds that were growing near the okra seedlings. Ousmane observed (Field Note, 21 June 2018) that the problem was that we had to take out "la rassina", because otherwise the weeds would grow again. When I asked him if he meant "racine", he responded affirmatively: evidently, he had given his best guess at an Italian translation of the French racine, "root", coming up with a non-existent but plausible (from a Frenchspeaking perspective) "rassina." To this, I replied "in italiano è radice", further translating his words into Italian. Once we apply a translation lens to translanguaging exchanges, it is possible to see how they are fuelled by translations, mistranslations, and collective negotiations on how to translate a certain word. This multilingual interaction is fuelled by Ousmane's need to find an Italian equivalent to a word that he already knows in French, reframing it into another system of signs to make himself understood. My own translation of his "rassina" has the ambiguous features of translation as linguistic hospitality. On one hand, it acknowledges that his utterance was not simply wrong, but a legitimate reflection of Ousmane's journey across languages; but on the other, it establishes the standard Italian translation of "racine" as the correct one that he should use in the future ("in italiano è radice").

At the same time, this interaction was predicated on material resources and the tasks at hand. As Pennycook and Otsuji noted in a Sydney market, the key to 
understanding street interactions is that "language is important to them in their constant transactions but so too is the price of parsley" (2015:3). In the episode above, I could understand Ousmane based on my knowledge of French, but most importantly on the fact that I was there too extirpating weeds. A few minutes later, Ousmane asked for "quella cosa che va sotto terra" "that thing that goes underground"), accompanied by an eloquent gesture. As my notes record, I initially thought of teaching him the word "paletta" ("trowel"); however, tired from the work and the heat, I just pointed at where the tool was and resumed work. The garden context did not erase inequalities between us, in the political (native vs. refugee) or linguistic (teacher vs. student) sense. Unlike the classroom, however, sharing agricultural tasks involved different communicative resources (such as gestures), and made the meaning of materiality (roots, leaves, stones, soil) highly relevant, for the skills that were needed to bring it out and handle it.

In my notes from 30 July, a Malian participant saw me using a hoe and joked "certo che Andrea se dovessi vivere con l'agricoltura moriresti di fame" ("Andrea if you had to farm for a living, you'd starve for sure"). Another participant, who at the beginning had appeared very conscious of hierarchy and would always address me with the formal "lei" instead of the informal "tu", joined in laughter. As a language teacher, I suddenly found myself in an environment where standard Italian became less important than each one's actions in relation to a conglomerate of soil, plants, tools. Linguistic practices became gradually more relaxed, and formality gradually shifted (the participant would no longer use "lei" with me) through the performance of shared tasks, also due to Tamat's insistence on involving the participants in the decisional process. At the time of this episode, two months into the UAL, participants were joining in discussions on cultivation strategies, and actively debating plans on what do to with the okra: some wanted to sell it to African shops, others would donate it to charitable organisations, and others were keen on selling it to Italians, believing that this would improve perceptions of African migrants among locals. These discussions would take place in person and in a WhatsApp group, indifferently in Italian or English, with sporadic French. The language policy showed its potential and limits: on the one hand, discussions were multilingual, and participants were encouraged to speak their mind without paying attention to Italian grammar and syntax; on the other hand, the staff necessarily ignored the plethora of languages that were spoken by participants (although they naturally did use them among themselves), to concentrate on nationally or globally relevant languages.

The Italian staff included agronomists, together with social workers who had personal experience in agriculture; they however did not know much about okra, which eventually played a big part in balancing the directionality of translation. Participants could decipher the okra plants as signs (ripening fruits, wilt- 
ing leaves) carrying specific meanings that were not so evident to us. Someone who is familiar with okra may have realized, by looking at Figure 1, that the fruits in the foreground are very big, and therefore probably fibrous to the point of being almost inedible: okra must be picked when small. The UAL staff (including myself), upon seeing them for the first time after a few days' absence, took the size of the fruits as a sign of a good harvest; the participants could interpret the sign correctly and predict that most fruits would not be good. This resulted in Giuli and the others being the judges of when okra was ripe to be picked, and negotiating the quantity of water for irrigation with the agronomists. Individuals with different types of agricultural expertise and backgrounds compared methods, triangulating their respective practical knowledges of the local soil and of the plant to be 'translated'.

The November 2018 interview underlines how extended and ramified Giuli and Bouliwell's knowledge of okra is, ranging from cultivation methods, to recipes and the textile uses of okra fibres. They recall these uses as a structured set of instructions that have been passed on to them:

Excerpt 1. RESEARCHER: e come medicina? perché io ho sentito che tipo c’è chi lo usa per il diabeteand as medicine? because I heard that, like, someone uses it for diabetes

BOULIWELL: sì si anche questoyes yes that too

GIULI: sì... in questo caso le persone che hanno diabeteyes... in this case people who have diabetes

RESEARCHER: $\mathrm{mh} \mathrm{mh}$

GIULI: si mangiano crudoeat it raw

RESEARCHER: così [crunch]like this [crunch]

GIULI: sì a volte a volte anche quando qualcuno si cucina riso comeyes sometimes sometimes also when someone cooks rice likeper esempio quando facevi quando cucinavi eh riso con l'okrafor example when you'd cook eh rice with okra

RESEARCHER: $\mathrm{mh} \mathrm{mh}$

GIULI: senza mettere al- altri prodotti come per esempio mettere olio rossowithout using other ingredients such as for example red oilolio questa cosa olio di palma tutto... niente no?oil that thing palm oil anything else... nothing, okay?

RESEARCHER: $\mathrm{mh} \mathrm{mh}$

GIULI: si mette solo il riso e si cucina l'okra e si mette dentroyou just put rice and cook okra and put it in 
Giuli not only knows the health value that his culture attributes to okra, but he immediately reformulates it as a series of code and procedures. As a folk remedy against diabetes, okra is cooked with rice, without palm oil or other ingredients: that presupposes a series of recipes and practices where okra is indeed cooked with oil etcetera, which Giuli implicitly construes as the "normal" use. The fact that palm oil is the default cooking fat for Giuli while being highly disregarded in Italy is also significant: the meaning of food cannot be taken for granted in its shifting links to local taboos, ideologies, and habits.

In Kant and the Platypus ([1997] 2016), Eco borrowed from chemical terminology to distinguish between what he calls the Nuclear Content and the Molar Content of a concept. While the former is a basic shared definition (e.g.: a horse is a four-legged animal that can be ridden), the Molar Content is a body of expanded encyclopaedic knowledge (e.g. the fact that a horse is an ungulate, or that Medieval knights put suits of armour on their horses). The Molar Content of food generally includes recipes, eating habits and ideologies/taboos (Parasecoli, 2011: 658) - and when saying that okra 'means' something different to Italians and refugees from West African countries, we are describing different extensions of this type of Content, such as the one described in Excerpt 1. The idea that okra carries different meaning for different communities coexisting in Perugia must not lead us to think of some innate knowledge that naturally pertains to a community, but rather of a different history of engagement with the same object that has shaped the individuals' semiotic repertoire. Translation, in its many forms, helps individuals work through this difference.

Within the context of the UAL, exploring this Molar content also helped to dispel the idea that okra was part of an all-encompassing "African" cuisine. When participants discussed their favourite okra recipes, variations in ingredients and preparation indexed differences between (for example) Nigeria and Guinea, as well as communicating to the Italian staff the complexity of semiofoodscapes whose nuances may not be automatically evident to them. A further layer of translation came from the fact that they all had to negotiate Italian terms for the ingredients and practices of home. When Bouliwell explained that in Guinea "c"è riso piccolissimo che si chiama fonio" ("there is a very small rice called fonio"), he referred to Digitaria Exilis, which is in fact a type of millet. In translating it as "riso", he found the best approximation (based on shape of the grain, and preparation) in his repertoire of Italian words. Bouliwell's utterance has to do with translation in the Peircean sense that one possible meaning of "fonio" is its translation into "riso piccolissimo"; translation as "glossing", reframing to be understood in a different context (Gal, 2015:227). The loss of meaning is also in this case the result of Bouliwell trying to be accommodated into the grammar of food of his Italian interlocutor (and not vice versa), with him doing most of the work to bridge the 
distance. As the next section will show, this is an important part of the strategy of translating foreign food, which shows power relations that the UAL did not completely erase, and that became especially apparent when Bouliwell and Giuli met with members of the Italian public.

\section{In the market}

The members of the UAL decided in August 2018 that the best use for excess okra would be to present it to Italian customers, to show the enterprise as an example of successful collaboration between Africans and Italians. Giuli spent one day at a farmers' market with a few crates of okra, near the stand of a young organic farmer who helped in the UAL out of personal investment in the refugees' cause. This section examines Giuli's narrative of his brief experience selling okra, outlining the translational aspects of these interactions as he moved outside of the UAL context and confronted a wider range of individuals. I will show how he created different strategies for communicating okra to two groups - those who already knew okra and those who did not - and how he did this by variably indexing the values of genuineness and healthiness; translating the okra as an exotic delicacy and himself, by reflection, as a purveyor of exoticism.

In their grocery shop study, Pennycook and Otsuji observe how individuals from different cultural and linguistic background often come together around wares that connect them to distant places: "artefacts [...] interpellate people, with implications for the multilingual resources that are then put into place" (2017: 447). As Giuli's example will also show, translation plays a role in discussing with potential customers who are "interpellated" by the artefacts in different ways. Marais's survey of translation among street peddlers in South Africa underlines how street transactions in multicultural settings thrive on a wealth of translation strategies, so that in many cases "the translation action and the business action are not separated" (2014:203). A translation lens is particularly important in this type of multilingual market study, since it can show how the balance of negotiations of product names, recipes etc., generally favours the customer's language. The seller generally has more economic interest than the buyer in working to bridge any communicative distance; in the case of a migrant seller, it generally means an effort to translate their wares into the language of the host community.

During the interview, Giuli divided his account of communicative strategies in two types, based on two groups of customers. The first group was made of individuals from several migrant communities, who knew okra already: 
Excerpt 2. GIULI: tanti perché ho alcuni ragazzi nigeriani o africani che ha preso il mio numerolots of people there are still Nigerian or other African guys who took my numberfino a oggi mi sta chiamando per l'okrathey are still calling me about okra to this day

RESEARCHER: [laughs]

GIULI: eh ... c'era anche alcuni cinesi che dicono che io lo so prodottothere were also Chinese people who said I know the producto arabi no dell'Asia no? che dicono che io lo so questo prodotto e lo cercavo in realtàor Arabs no? from Asia, no? who said I know this product and I have been looking for it actuallyperò questi sono molto buoni questi sono molto freschibut these are very good these are very fresh

RESEARCHER: okay

GIULI: per trovare okra così in a Perugia è una cosa difficile dove l'avete piantato?it is difficult to find okra like this in Perugia where did you plant it?Hai visto come si che cosa si produce?Have you seen how it is made?

RESEARCHER: okay

GIULI: $e$ io dico che noi questi non hanno portati da nessun parteand I say these were not brought in from anywhereli abbiamo piantato quie stamattina li abbiamo raccolti ... o ieri pomeriggiowe planted them here and picked them this morning ... or yesterday afternoon

Individuals from a variety of backgrounds (Nigerian, Arab, Chinese) are united by the fact that okra is a staple of their home cuisines. During fieldwork, the only other place where I saw okra were African shops: secluded indoor spaces, explicitly connotated as "ethnic", selling imported wares. It is no wonder that, based on Giuli's narrative, members of different communities were surprised to find fresh okra at the farmers' market. Cavanaugh has observed how producers at farmers' market in Northern Italy mobilize linguistic resources that include local dialects, narratives about the local provenance of foods, and a "co-constructed display of shared food values" to engage with customers (2016:49). This is because one can apply certain positive qualities (freshness, genuineness, trustworthiness) to locally grown food with respect to imported food. Giuli does not index - for obvious reasons - regional ideologies of what constitutes good food; but his brief narrative about freshly picked okra partakes similarly in the ideology that locally grown food is genuine and trustworthy ("non hanno portati da nessun parte") combined with okra's power to represent 'home' for so many communities. This is how he attempts to frame his okra as better than the one in the African shops.

Okra interpellates (Pennycook \& Otsuji, 2017) different people at the market, and an important factor in their reaction is whether the vegetable is already part 
of their grammar of food or not. As noted above, self-representation rather than economic gain was the main drive of Giuli and Bouliwell's effort: when in the interview Bouliwell talks about a similar outing that the group did at a fair-trade festival in Città di Castello near Perugia, he comments positively about the fact that many people stopped at their stand and that Italian organic famers showed curiosity in okra, rather than the sales that were made. It seems reasonable then, that Giuli would remark at length about the strategies that he used to talk to Italian customers who did not know okra. Giuli describes how some approached him with curiosity - significantly, his narrative does not mention whether any passersby avoided his stall, out of diffidence or simple lack of interest. He talks about the communicative strategies he employed to 'translate' okra to the curious:

Excerpt 3. GIULI: quelli che non sanno dicono che che tipo di frutta è questo?those who do not know ask what what type of fruit is this?perché io non l'ho mai visto ebecause I have never seen it, ande mi potete spiegare un po' che sapore ha questo o che benefiche ha questo?and can you explain what it tastes like or if it has health benefits? e noi veniamo a spiegarloso we explain

RESEARCHER: okay

GIULI: e quando spieghiamo subito loro compranoand when we explain they buy it immediately

RESEARCHER: quando spieghi che cosa cosa gli dici? [...]what do you say when you explain?

GIULI: eh l'okra ... e le le benefiche che ha l'okra spieghiamo magari...well okra ... and the health benefits of okra we explain maybe...ehm è un prodotto che è simile con peperoncino fra peperoncino e melanzanaer it is a product that is similar to chili pepper, between chili pepper and auberginee anche ha benefiche per le persone che curano le diabeteand it also has benefits for those who have diabetes

RESEARCHER: okay

GIULI: e come si cucina solo questo spieghiand how you cook it that's what you explain

Confronted with the alterity of an unfamiliar green foodstuff interpellating them, passers-by ask Giuli. It will not be enough for him to simply name it as "okra": Giuli notes that when people ask about okra, they ask for an expanded meaning, which includes its taste and value - that people are asking not for okra's dictionary meaning, but what it may potentially mean to them. This is where Giuli becomes a food translator, as the task requires him to find words that will be understood by the target audience, smoothing its alterity for the benefit of the customers. He 
appears aware that his okra may have value out of its capacity to index cultural difference; and mobilized the semiosis of food on different levels (taste, uses, health value) in ways that simultaneously underlined its exoticism and brought it closer to the Italian public.

The most basic element of food semiosis is its being recognized as edible or not by taste buds: "flavor sensors might function as border points of semiosis, allowing new extraneous substances to become part of the system, or to be refused" (Parasecoli, 2011: 651). A key feature of the semiosis of food is the capacity to move up the scales of indexicality, from basic embodied meaning through different levels of complexity, up to the capacity of food-language and practices to index religious values, cultural belonging, or social class "as a means of psychologically satisfying validation of identity” (Silverstein, 2006:493).

Here, Giuli begins by turning the embodied meaning of taste into Italian words. Marais calls this type of sensorial shift a translation on the basis that "olfactory information about a dish will lead to a different interpretant than auditory or visual information about the same dish" (2019:146). Translating flavour into words means changing the representamen (the material/mental entity that stands for an object in Peircean semiotics) associated with that food. In translating flavour into words, we keep relating to the same object (a specific food), but we create new interpretants for that food, i.e. enable people to say and think different things about it. These can be translated in turn by gestures, rituals, speech etc. In Giuli's case, this chain of interpretants associates this meaning with meaning that both interlocutors know, creating a form of agreement, even if some parts of the meaning is lost. Saying that okra tastes 'halfway between pepper and aubergine' is an approximation, but one that enables Giuli to bridge the communicative gap.

Something like Giuli's translation of okra (or Bouliwell's translation of fonio, above) happens when we translate ravioli and gyoza as, respectively, Italian and Japanese dumplings. In this case, we are not claiming identity between dumplings, ravioli and gyoza; actually, we lose several features of ravioli-ness and gyoza-ness that constitute their Molar Content (geographical origin, fillings etc.). Rather, we are underlining similarities that make the first two understandable to an Englishspeaking audience using their shared definition of another object. The inevitable loss of some features from the source is an old translator's adage (more often applied to poetry than to dumplings), but something is also gained here in the fact that the object is made understandable to a new audience. As Tyulenev noted, translation has to do with compromise between the interlocutors' life-worlds, "who without translation would be doomed to stay in their impenetrable bubbles", enabling them to "exchange their opinions, sometimes agreeing, sometimes disagreeing, but always learning something about one another" (2018:76). In the 
food market, it becomes very evident how this type of food translation intersects with the politics of hospitality: from the position of 'guest', Giuli works to bridge the communicative distance between flavour and word in a way that privileges the Italian interlocutors, to make okra sound familiar and desirable to the 'host'.

If the meaning of okra lies in a complex conglomerate of taste, culture, and economics, Giuli selects features of the Molar content that will make it potentially appealing to the Italian public. Moving across the scales, this includes okra's use as a folk remedy against diabetes, and basic recipes ("e come si cucina"). In talking about okra's "benefiche", Giuli is stressing healthiness: while I have not collected data on customers' responses to okra, healthiness is probably a successful selling point at a farmers' market, whose customers may be receptive to the idea that certain foods are 'good for you' (Cavanaugh, 2016). This is possibly combined with the 'exotic' character that is normally bestowed on African food in the West (Workneh, 2020), and that may arise interest in 'foodies' in search of novelty and authenticity. 'Exoticism' and 'authenticity' in food operate, however, as a "double-edged sword" in that they grant acceptability and even desirability to non-Western foods only to the extent that they "do not stray too far towards strangeness" (Oleschuk, 2017:221). Giuli appears to know this instinctively as he reframes the alien taste of okra and stresses its use as a folk remedy in 'Africa, indexing it as a remedy that comes from afar and will bring benefits to the consumer. Asked about okra's taste, uses and value, he strategically reframed the okra's taste, uses and value in terms that would not only be understandable but appealing to Italian customers. He succeeds by stressing the cultural difference indexed by okra, in a way that simultaneously bridges the communicative gap in favour of Italian tastes and desires. This is relevant to his and Bouliwell's desire to be accepted into the local community, which is an important part of why they decided to take part in the UAL in the first place.

\section{Conclusions}

Through the presentation of my involvement with a community gardening project, it was my intention to document the different practices of language contact and translation between the beneficiaries and the staff of an NGO project. In doing so, I underlined the role of translation as the ability to reframe meaning across semiotic systems, predicated on a specific task, material/immaterial resources, and power relations between interlocutors.

The study was focused, by design, on the close analysis of the evolving linguistic repertoire of a small group of participants. As such, it has mostly considered significant micro-interactions that have shaped the socio-political dimension 
of language and translation in their experience, in relation with teachers, social workers and members of the public. The latter were explored in terms of how the participants frame these interactions within the scope of their own trajectories. As for the limitations of this approach, future studies may expand the scope of research to include an analysis of more public contexts of interaction, analyzing the arrival of a new immigrant food (like okra) in a local economic market and the reactions of local public.

The ethnography in this article has shown the creation of a space where the NGO staff and asylum seekers were engaged in the same task with a view to responsibility-sharing, which also enabled asylum seekers to make use of their complex and multifaceted awareness of agricultural and food practices. With respect to other types of "integration" activities, such as the classroom training that preceded the creation of the garden, the material and physical nature of the gardening activity had a positive impact on the directionality of communication.

The interview shows how Giuli performed his role as a mediator between different cultures and foodways, with the staff (as the provider of culture-specific knowledge), with other migrants (as the provider of genuine food from 'home') and with Italian customers (as purveyor of a new and exotic vegetable). By offering locals a tangible element of their culinary culture, Giuli and Bouliwell also offered an image of themselves as producers and intercultural brokers, rather than asylum seekers with a specific place assigned by the Italian state. Their expertise empowered them to a degree even if, it must be noted, an analysis of their communicative strategies reveals how the power relations between the customers (hosts) and Giuli (guest) remained in place for the exchange, and influenced Giuli’s translation strategies.

This research offers a contribution towards the study of translation as a political force; and towards an interdisciplinary dialogue between translation studies and other disciplines. A deeper engagement with a world of embodied semiosis and practices, considering translation not as an interlingual operation but as the reformulation of meaning into other meaning, is the natural convergence of translation studies with applied linguistics, linguistic anthropology, and social semiotics. These tools enable the study of non-linguistic meaning as not an obstacle or afterthought to translation, but a part of the human capacity to translate. Food is particularly powerful in this sense, for its capacity to pack different meaning together with its flavour. 


\section{Funding}

This project has received funding from the Irish Research Council and from the European Union's Horizon 2020 research and innovation programme under the Marie Skłodowska-Curie grant agreement No. 713279. This publication reflects only the author's views, and the IRC or the REA are not responsible for any use that may be made of the information it contains.

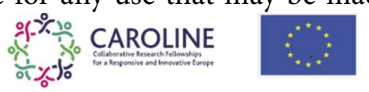

\section{Acknowledgements}

I would like to thank Patrizia Spada and Domenico Lizzi for helping me navigate through the world of NGOs. I would also like to thank the two anonymous reviewers, and LCS editor Alfonso Del Percio, for their helpful and insightful comments on different drafts of this article.

\section{Bibliography}

Abbots, E. J. (2011). “It doesn't taste as good from the pet shop”: Guinea pig consumption and the performance of transnational kin and class relations in highland ecuador and new york city. Food, Culture and Society, 14(2), 205-223. https://doi.org/10.2752/175174411X12893984828755

Barthes, R. (1961). Pour une psycho-sociologie de l'alimentation contemporaine. Annales. Economies, Sociétés, Civilisations, 16(5), 977-986. https://doi.org/10.3406/ahess.1961.420772

Baynham, M., \& Lee, T.K. (2019). Translation and Translanguaging. Oxford: Routledge. https://doi.org/10.4324/9781315158877

Blommaert, J. (2010). The sociolinguistics of globalization. Cambridge: Cambridge University press. https://doi.org/10.1017/CBO9780511845307

Carlsen, H. B., Doerr, N., \& Toubøl, J. (2020). Inequality in Interaction: Equalising the Helper-Recipient Relationship in the Refugee Solidarity Movement. Voluntas. https://doi.org/10.1007/s11266-020-00268-9

Cavanaugh, J.R. (2013). Il y a kébab et kébab: Conflit local et alimentation globale en Italie du nord. Anthropologie et Sociétés, 37(2), 193-212. https://doi.org/10.7202/1017912ar

Cavanaugh, J.R. (2016). Talk as work: Economic sociability in Northern Italian heritage food production. Language and Communication, 48, 41-52.

https://doi.org/10.1016/j.langcom.2016.02.001

Ceccarelli, G., \& Ciconte, F. (2018). Human suffering in Italy's agricultural value chain. Retrieved from https://policy-practice.oxfam.org.uk/publications/human-suffering-initalys-agricultural-value-chain-620479

Chiaro, D., \& Rossato, L. (2015). Introduction: Food and translation, translation and food. The Translator, 21(3), 237-243. https://doi.org/10.1080/13556509.2015.1110934

Ciribuco, A. (2020). How Do You Say Kélén-Kélén in Italian? Migration, Landscape and Untranslatable Food. Translation Studies, 13(1), 99-115. https://doi.org/10.1080/14781700.2019.1662837. 
Creese, A., Blackledge, A., \& Hu, R. (2018). Translanguaging and translation: the construction of social difference across city spaces. International Journal of Bilingual Education and Bilingualism, 21(7), 841-852. https://doi.org/10.1080/13670050.2017.1323445

Cronin, M. (2017). Eco-Translation. Translation and ecology in the age of anthropocene. Oxford: Routledge. https://doi.org/10.4324/9781315689357

Cronin, M., \& Simon, S. (2014). Introduction: The city as translation zone. Translation Studies, 7(2), 119-132. https://doi.org/10.1080/14781700.2014.897641

De Costa, P.I. (2010). From Refugee to Transformer: A Bourdieusian Take on a Hmong Learner's Trajectory. TESOL Quarterly, 44(3), 517-541. https://doi.org/10.5054/tq.2010.226856

De Marco, A. (2015). Are green-lipped mussels really green? Touring New Zealand food in translation. The Translator, 21(3), 310-326. https://doi.org/10.1080/13556509.2015.1103098

Del Percio, A. (2016). The governmentality of migration: Intercultural communication and the politics of (dis)placement in Southern Europe. Language and Communication, 51(February), 87-98. https://doi.org/10.1016/j.langcom.2016.07.001

Del Percio, A. (2018a). Engineering commodifiable workers: language, migration and the governmentality of the self. Language Policy, 17(2), 239-259. https://doi.org/10.1007/s10993-017-9436-4

Del Percio, A. (2018b). Language, communication, and the politics of hope: Solidarity and work in the Italian migration infrastructure. Langage et Societé, 165(3), 95-115. https://doi.org/10.3917/ls.165.0095

Desjardins, R., Cooke, N., \& Charron, M. (2015). Food and translation on the table: Exploring the relationships between food studies and translation studies in Canada. The Translator, 21(3), 257-270. https://doi.org/10.1080/13556509.2015.1103095

Eco, U. (2016). Kant e l'ornitorinco (2nd ed.). Milano: La nave di Teseo.

Flubacher, M.C., \& Yeung, S. (2016). Discourses of integration: Language, skills, and the politics of difference. Multilingua, 35(6), 599-616. https://doi.org/10.1515/multi-2015-0076

Flynn, P. (2010). Ethnographic approaches. In Y. Gambier \& L. van Doorslaer (Eds.), Handbook of Translation Studies (pp. 116-119). Amsterdam: John Benjamins. https://doi.org/10.1075/hts.1.eth2

Flynn, P., \& van Doorslaer, L. (2016). City and migration: a crossroads for noninstitutionalized translation. European Journal of Applied Linguistics, 4(1), 73-92. https://doi.org/10.1515/eujal-2015-0032

Footitt, H., Crack, A., \& Tesseur, W. (2020). Development NGOs and Languages: Listening, Power and Inclusion. Cham: Palgrave Macmillan. https://doi.org/10.1007/978-3-030-51776-2

Gal, S. (2015). Politics of Translation. Annual Review of Anthropology, 44, 225-240. https://doi.org/10.1146/annurev-anthro-102214-013806

Garzone, G. (2017). Food, culture, language and translation. Journal of Multicultural Discourses, 12(3), 214-221. https://doi.org/10.1080/17447143.2017.1364255

Giordano, C. (2014). Migrants in Translation. Caring and the Logic of Difference in Contemporary Italy. Oakland CA: University of California Press. https://doi.org/10.1525/9780520958869

Greco, S. (2016). The semiotics of migrants' food: Between codes and experience. Semiotica, 2016(211), 59-80. https://doi.org/10.1515/sem-2016-0089 
Hamaidia, L., Methven, S., \& Woodin, J. (2018). Translation spaces: Parallel shifts in translation and intercultural communication studies and their significance for the international development field. Translation Spaces, 7(1), 119-142. https://doi.org/10.1075/ts.00007.ham

IDOS, C. studi e ricerche. (2017). Dossier statistico immigrazione. Roma.

Inghilleri, M. (2005). Mediating zones of uncertainty: Interpreter agency, the interpreting habitus and political asylum adjudication. The Translator, 11(1), 69-85. https://doi.org/10.1080/13556509.2005.10799190

Inghilleri, M. (2017). Translation and Migration. New York: Routledge.

Järlehed, J., \& Moriarty, M. (2018). Culture and class in a glass: Scaling the semiofoodscape. Language and Communication, 62, 26-38. https://doi.org/10.1016/j.langcom.2018.05.003

Jiménez-Ivars, A., \& León-Pinilla, R. (2018). Interpreting in refugee contexts. A descriptive and qualitative study. Language and Communication, 6o, 28-43. https://doi.org/10.1016/j.langcom.2018.01.009

Karrebæk, M.S. (2017). Thai veggies and hair removal products: space, objects and language in an urban greengrocery. Social Semiotics, 27(4), 451-473. https://doi.org/10.1080/10350330.2017.1334394

Karrebæk, M.S., Riley, K.C., \& Cavanaugh, J.R. (2018). Food and Language: Production, Consumption, and Circulation of Meaning and Value. Annual Review of Anthropology, 47(1), 17-32. https://doi.org/10.1146/annurev-anthro-102317-050109

Li, S. (2019). A corpus-based multimodal approach to the translation of restaurant menus. Perspectives: Studies in Translation Theory and Practice, 27(1), 1-19. https://doi.org/10.1080/0907676X.2018.1483408

Marais, K. (2014). Translation Theory and Development Studies. A Complexity Theory Approach. New York: Routledge. https://doi.org/10.4324/9780203768280

Marais, K. (2019). A (bio)semiotic theory of translation. New York: Routledge.

Musarò, P., \& Parmiggiani, P. (2017). Beyond black and white: the role of media in portraying and policing migration and asylum in Italy. International Review of Sociology, 27(2), 241-26o. https://doi.org/10.1080/03906701.2017.1329034

Oleschuk, M. (2017). Foodies of Color: Authenticity and Exoticism in Omnivorous Food Culture. Cultural Sociology, 11(2), 217-33. https://doi.org/10.1177/1749975516668709

Parasecoli, F. (2011). Savoring semiotics: Food in intercultural communication. Social Semiotics, 21(5), 645-663. https://doi.org/10.1080/10350330.2011.578803

Pennycook, A., \& Otsuji, E. (2015). Metrolingualism. Language in the city. Oxford: Routledge. https://doi.org/10.4324/9781315724225

Pennycook, A., \& Otsuji, E. (2017). Fish, phone cards and semiotic assemblages in two Bangladeshi shops in Sydney and Tokyo. Social Semiotics, 27(4), 434-450. https://doi.org/10.1080/10350330.2017.1334391

Piller, I. (2016). Linguistic diversity and social justice. An introduction to applied sociolinguistics. New York: Oxford University Press. https://doi.org/10.1093/acprof:oso/9780199937240.001.0001

Ricœur, P. (2006). On Translation. (E. Brennan, Trans.). London: Routledge.

Riley, K.C., \& Cavanaugh, J.R. (2017). Tasty Talk, Expressive Food: An Introduction to The Semiotics of Food-and-Language. Semiotic Review, (5), 1-12. Retrieved from https:// semioticreview.com/ojs/index.php/sr/article/view/1

Sen, A. (2016). Food, place, and memory: Bangladeshi fish stores on Devon Avenue, Chicago. Food and Foodways, 24(1-2), 67-88. https://doi.org/10.1080/07409710.2016.1145026 
Silverstein, M. (2006). Old wine, new ethnographic lexicography. Annual Review of Anthropology, 35, 481-496. https://doi.org/10.1146/annurev.anthro.35.081705.123327

Silverstein, M. (2016). Semiotic Vinification and the Scaling of Taste. In E.S. Carr \&

M. Lempert (Eds.), Scale: Discourse and Dimensions of Social Life (pp. 185-212). Oakland CA: University of California Press.

Tesseur, W. (2017). Incorporating translation into sociolinguistic research: Translation policy in an international non-governmental organisation. Journal of Sociolinguistics, 21(5), 629-649. https://doi.org/10.1111/josl.12245

Tyulenev, S. (2018). Translation in the public sphere. Cham: Palgrave Macmillan. https://doi.org/10.1007/978-3-319-78358-1

Vigouroux, C. (2019). Language and (in) Hospitality. The Micropolitics of Hosting and Guesting. Language, Culture and Society 1(1), 31-58. https://doi.org/10.1075/lcs.00003.vig

Workneh, T. (2020). Exotica Africana: Interrogating African Otherness in Bizarre Foods with Andrew Zimmern. Popular Communication 18(2), 121-37.

https://doi.org/10.1080/15405702.2019.1637524

\title{
Address for correspondence
}

\author{
Andrea Ciribuco \\ Department of Languages, Literatures, \& Cultures \\ National University of Ireland, Galway \\ University Road \\ Galway $\mathrm{H}_{91} \mathrm{TK}_{33}$ \\ Ireland \\ andrea.ciribuco@nuigalway.ie
}

